\title{
ГОНЧАРНОЕ ПРОИЗВОДСТВО НА ТЕРРИТОРИИ ДРЕВНЕЙ ДЕЛЬТЫ СЫРДАРЬИ В ЭПОХУ АНТИЧНОСТИ: НОВЫЕ ДАННЫЕ
}

\author{
(C) 2020 г. С. Б. Болелов, Ж. Р. Утубаев
}

В статье публикуются результаты нескольких лет раскопок на поселении БабишМулла 7, на территории древней дельты Сырдарьи, где во второй половине I тыс. до н.э. была распространена земледельческая чирикрабатская археологическая культура. Бабиш-Мулла 7 - крупный производственный гончарный центр III-II вв. до н.э., снабжавший керамикой население крупного земледельческого оазиса. На поселении открыты двухъярусные керамические обжигательные горны двух типов. Прямоугольные горны 1-го типа по конструктивным признакам не имеют аналогий на территории Средней Азии. Рядом с горнами раскопаны производственные помещения, где изготавливалась посуда.

Ключевые слова: археология, древнеземледельческая культура, поселение, производственный центр, двухъярусный обжигательный керамический горн, керамика, гончарная мастерская

\section{Введение}

Поселение Бабиш-Мулла 7, которое является крупнейшим и наиболее изученным в настоящее время гончарным производственным центром не только на территории нижней Сырдарьи, но и в пределах всего Южного Приаралья, расположено на восточном берегу сухого русла p. Жанадарья в 5 км к ЮВ от городища Бабиш-Мулла 1. Общая площадь поселения приблизительно 1,6 га $450 \times 350$ м. Во всяком случае, именно на этом участке отмечены следы построек и хорошо видимые на поверхности современного такыра развалы обжигательных горнов (рис. 1; А). С запада к поселению был подведен канал-водохранилище шириной 15 м. Береговые отвалы до сих пор отчетливо прослеживаются на поверхности такыра (рис. 1; Б).

Описание материала

Максимальная концентрация предполагаемых построек и разва-

лов горнов фиксируется в южной части поселения. Именно сюда был подведен канал-водохранилище. Обжигательные горны, которые на поверхности четко прослеживаются в виде развала керамического шлака и печины, располагались как отдельно, на некотором удалении от предполагаемых построек, так и рядом с ними. Всего, в настоящее время, в результате визуального обследования поселения выявлено 11 обжигательных горнов, но, несомненно, их было больше. В южной части поселения, на уровне современной дневной поверхности, также в результате визуального обследования поселения, зафиксировано семь предполагаемых построек, которые могут быть как небольшими жилыми домами, так и мастерскими (рис. 1; А). На поверхности они определяются обширными скоплениями керамики, в некоторых случаях на поверхности видны контуры стен из 


\section{ҚАЗАҚСТАН АРХЕОЛОГИЯСЫ № 1 (7) 2020}
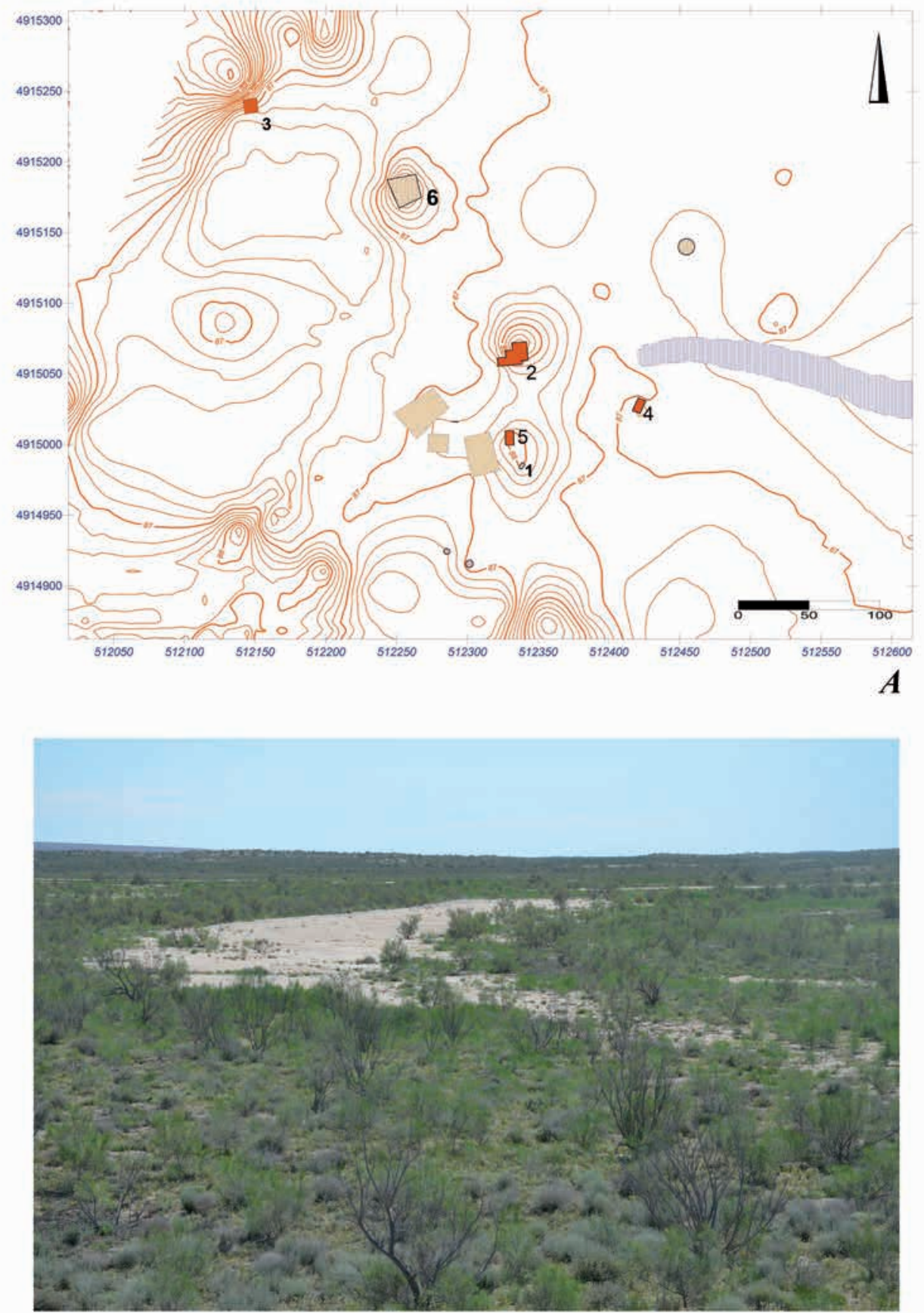

Рис. 1. Поселение Бабиш-Мулла 7. Фото авторов

Fig. 1. The settlement of Babish Mulla 7. Authors's photo 
Болелов С.Б., Утубаев Ж.P. Гончарное производство на территории древней дельты Сырдарьи в эпоху античности: новые данные

сырцового кирпича. Надо полагать, постройки сильно размыты, но, судя по скоплению керамики, характеру и цвету грунта на поверхности такыра, можно предполагать наличие культурного слоя на объектах.

В северо-западной части поселения на берегу сухого русла (расстояние до берега 50-60 м) обнаружена довольно крупная усадьба. На поверхности четко видны контуры стен помещений, сложенных из прямоугольного сырцового кирпича на пахсовом основании. Большая часть усадьбы в настоящее время погребена под барханом, но уже по открытым в ходе раскопок помещениям можно говорить, что это было большое многокомнатное здание. Площадь шести раскопанных помещений, с учетом того, что некоторые из них вскрыты не полностью, была не менее 200 кв. м (рис. 2). Принимая во внимание то, что открыто меньше половины здания, можно предположить, что общая его площадь, не считая дворов, была не менее 500-600 кв. м, а возможно и больше. Таким образом, если наши предположения верны, то усадьбу на поселении Баланды вполне можно сравнить с крупными и средними сельскими усадьбами античного Хорезма ${ }^{1}$. Так, например, площадь жилого дома усадьбы № 3 в Аязкалинском поселении, ранний слой которого датируется IV-III вв. до н.э., была немногим более 600 кв. м. $(18 \times 34$ м). Площадь жилых помещений - 340 кв. м. [Неразик, 1976, с. 40-43]. Планировка усадьбы на поселении Бабиш-Мулла 7 полностью не выявлена, по этой причине нам трудно отнести ее к какому-либо типу сельского жилища, выявленного в Хорезме. Осторожно можно предполагать, что это четвертый тип домов, выделенный Е. Е. Неразик, в котором чередуются крупные и мелкие поме- щения, расположенные в несколько рядов [Неразик, 1976, с. 159].

На территории поселения практически полностью раскопан жилищно-производственный комплекс (Раскоп 2 - Мастерская № 1), который включал в себя два обжигательных горна, производственные и жилые помещения (рис. 3) [Утубаев, Болелов, 2016, с. 56-62]. К югу от раскопа 2 частично открыт еще один производственный комплекс (мастерская № 2) (рис. 4), который, по всей видимости, являлся частью крупной усадьбы. Во всяком случае, об этом можно догадываться по планировкам построек, контуры которых прослеживаются на уровне современной дневной поверхности рядом с раскопанными горнами (рис. 1).

В 2019 году в северной части поселения, к югу от Усадьбы начаты раскопки еще одного производственного комплекса, где полностью раскопан обжигательный горн № 7 и вскрыта часть большого монументального здания рядом с ним (рис. 5). Кроме того, на территории поселения полностью раскопаны два обжигательных керамических горна и расчищен развал еще одного разрушенного горна. Все они расположены на некотором расстоянии от жилых и производственных помещений.

\section{Обсуждение материала}

Таким образом, на территории поселения Бабиш-Мулла 7 за пять полевых сезонов раскопано семь обжигательных горнов, гончарные мастерские и, частично, жилое здание - Усадьба. Полученные в ходе раскопок материалы открывают практически новую страницу в истории керамического производства Южного Приаралья.

Первые обжигательные горны, являющиеся безусловным свидетель- 
Условнье обозиачения.

AIIV- naxca.

$\square$ - сырщовый кирпи

ШШ - плотная глина

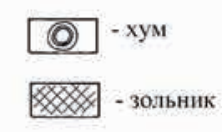

- зольник

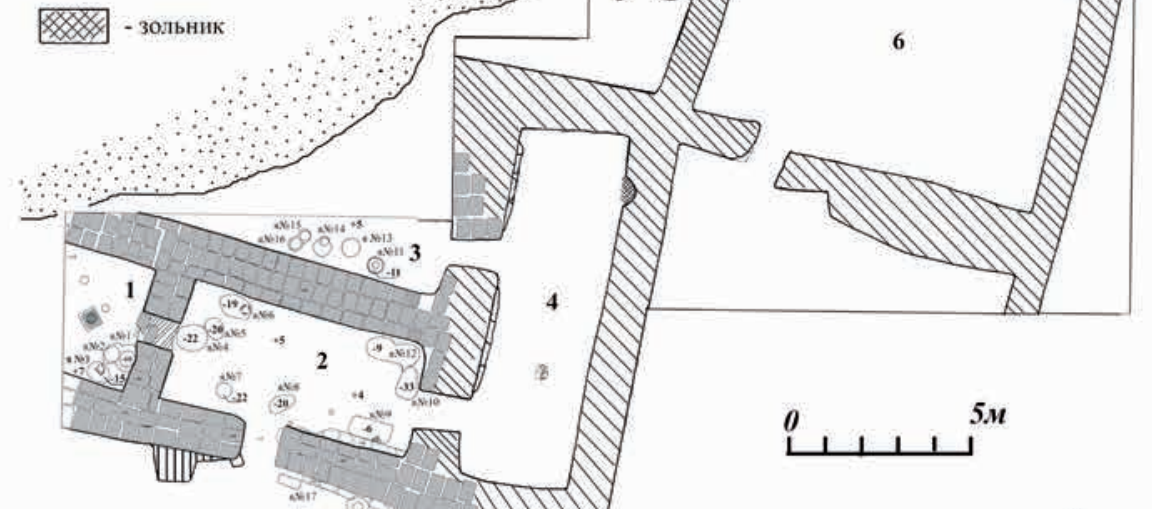

$\boldsymbol{A}$

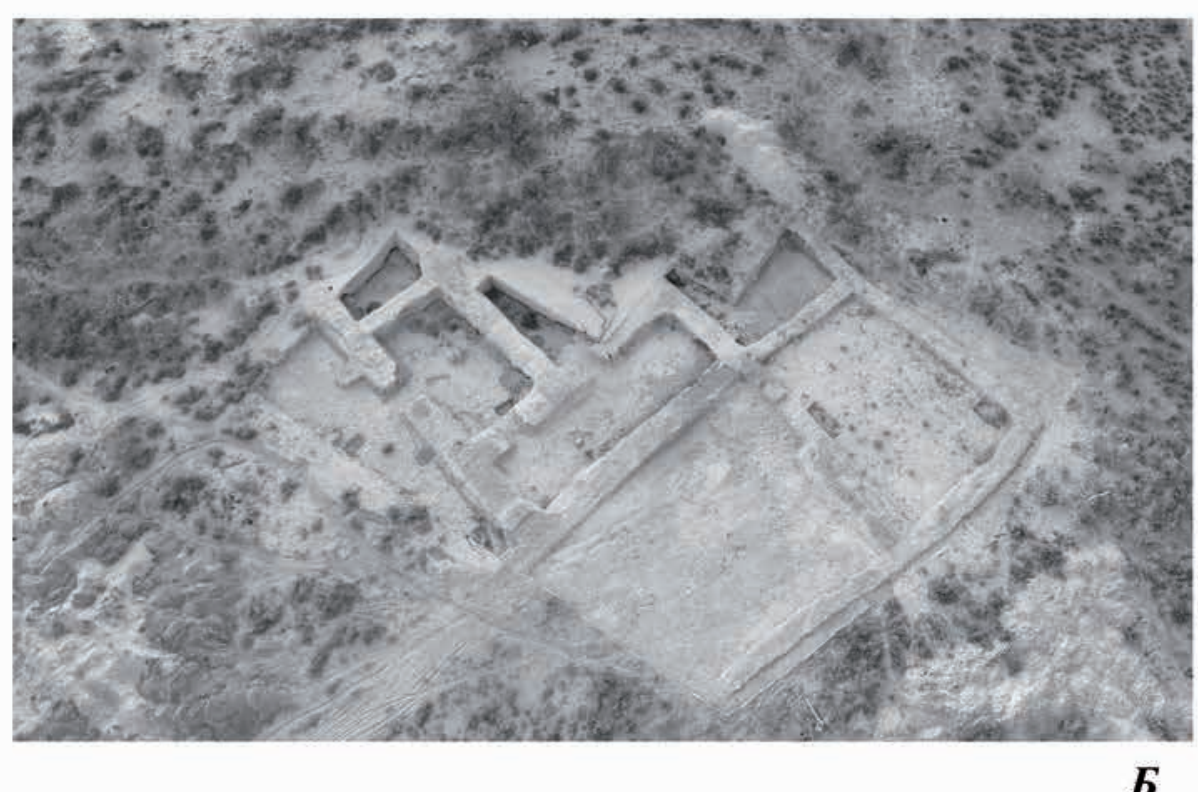

Рис. 2. Бабии-Мулла 7. Раскоп 3. Усадьба

Fig. 2. Babish-Mulla 7. Excavation 3. Manor 
Болелов С.Б., Утубаев Ж.Р. Гончарное производство на территории древней дельты Сырдарьи в эпоху античности: новые данные
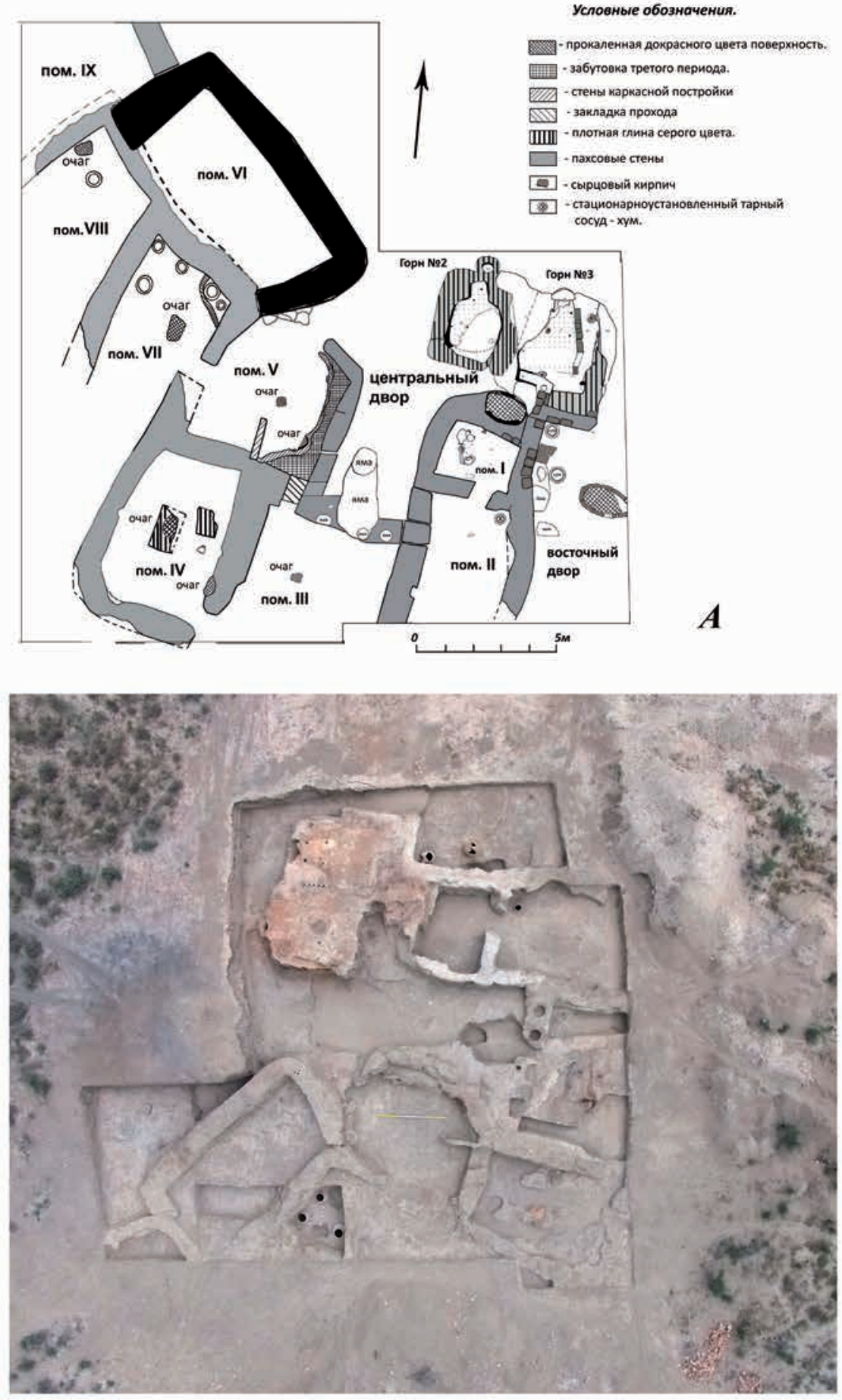

Рис. 3. Бабиш-Мулла 7. Раскоп 2

Fig. 3. Babish-Mulla 7. Excavation 2 


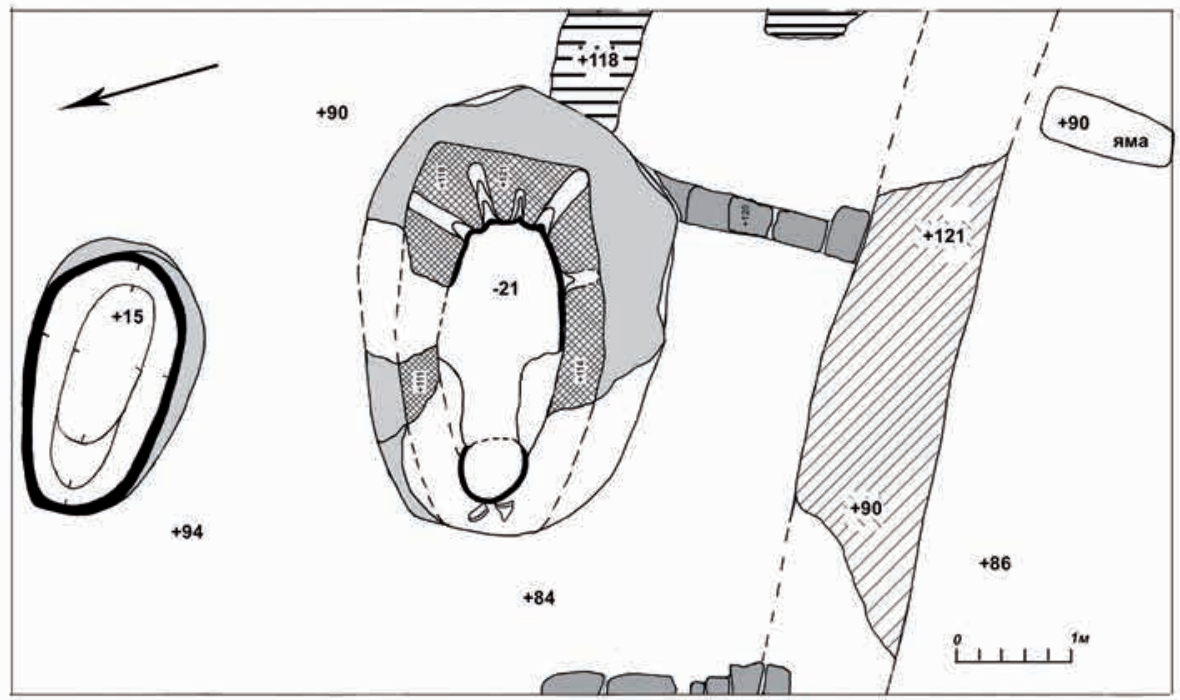

\section{Условные обозначения.}

$\square$ - пахсовая стена топочной камеры
Мा - стена помещения.
DD - плотная глина

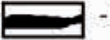

- ошлакованная поверхность топочной камеры

- прокаленная до красного цвета поверхность.

- сырцовый кирпич

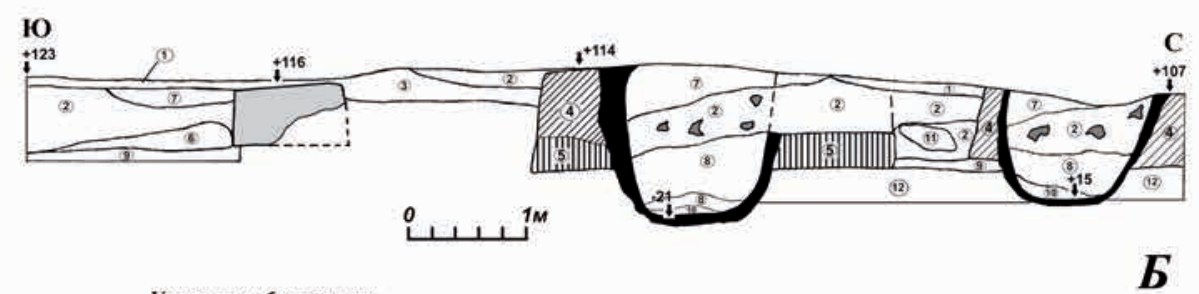

Условные обозиачешия.

1 - слой супеси серо-коричневого цвета.

9 - пзотний слонстый суглиной коричшевого ивета 10 - плопиый слой спекшейся солы и пепла серого швета.

11 - елой прокалениого до красного ивета песка
12 - плотый песок коричневого и светло-коричневого цвета.

обожжениой глины и керамического шакака.

3 - слой рыхлого комковатого суглинка серо-коричневого двета

с высоким содержанием золы

4 - плотная тлина-пахса

$\square$ - пахсовая стена в разрезе.

5- плотная глина серо-коричневого швета

6 - слой плотной комковатой гаииы коричневого цвета с кусками сыриового кирпича.

7 - рыхлая пьлевидная супесь серого швета

8. слой комковатого сугзинка красио-коричневого щвета с комками прокаленной

до красного ивета ганной и фрагментами ошлакованных кирпичей.

Рис. 4. Бабиш-Мулла 7. Раскоп 4. Мастерская 4

Fig. 4. Babish-Mulla 7. Excavation 4. Workshop 4 
Болелов С.Б., Утубаев Ж.Р. Гончарное производство на территории древней дельты Сырдарьи в эпоху античности: новые данные

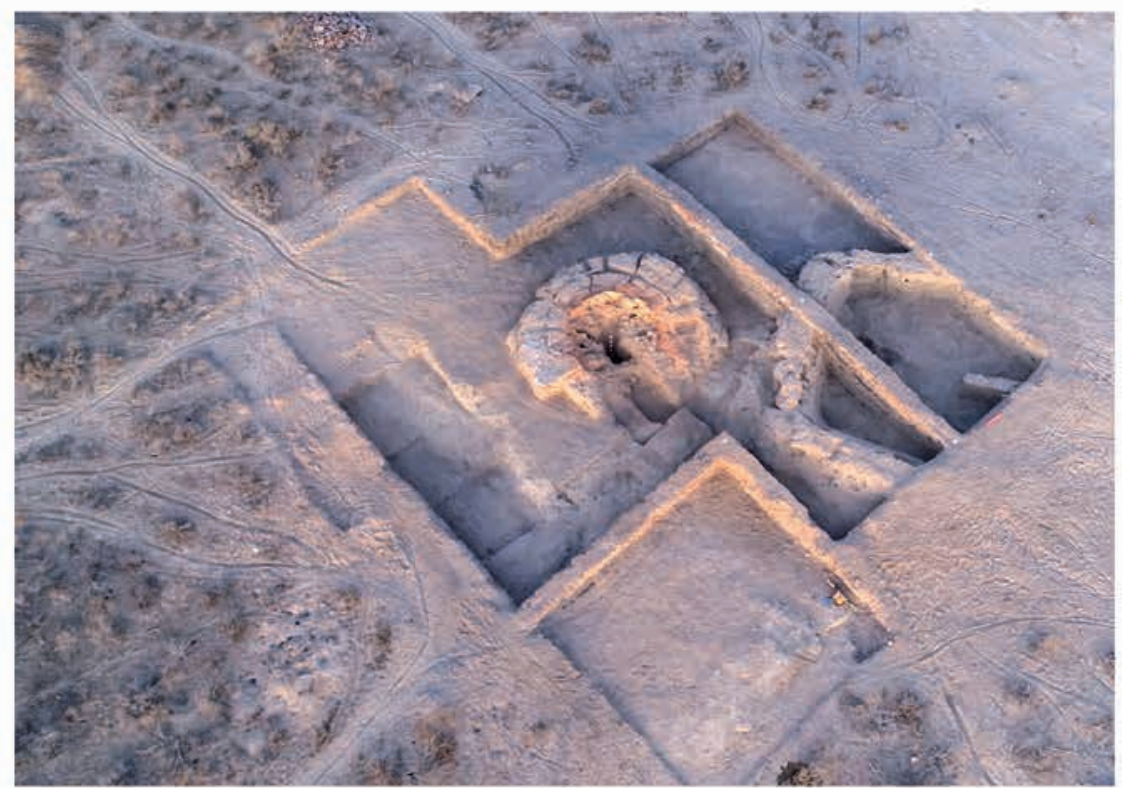

$\boldsymbol{A}$

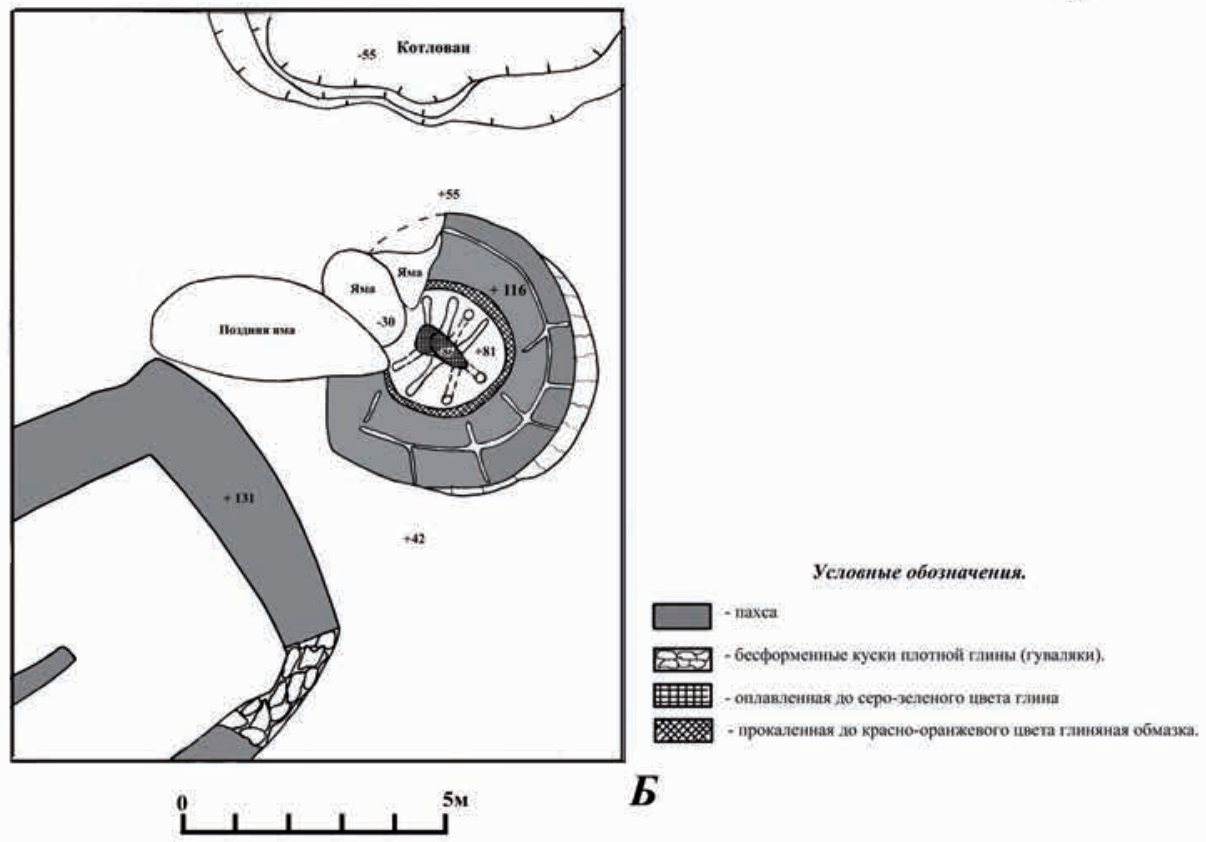

Рис. 5. Бабии-Мулла 7. Раскоп 6

Fig. 5. Babish-Mulla 7. Excavation 6 
ством существования ремесленного гончарного производства, были открыты в процессе раскопок городища Бабиш-Мулла 1 в начале 1960-х гг. В пределах входного айвана восточной части «Большого дома» на цитадели городища были открыты части топочных камер (ТК) нескольких горнов, относящихся к первому периоду существования памятника [Толстов и др., 1963, с. 63-64]. Горны были двухьярусные, прямоугольные в плане, длиной 2 м и шириной не более $1 \mathrm{M}$, с прямым вертикальным ходом горячих газов. Теплопроводные каналы (распределители тепла - РТ) в пределах тепловодно-разделительного блока $(\text { ТРБ })^{2}$ располагались параллельно друг другу и перпендикулярно относительно центральной продольной оси горна. В обжигательную камеру (ОК) они открывались округлыми в плане продухами [Воробьева, 1961, c. 171]. Остатки специальных обжиговых устройств были открыты на поселении Баланды. На усадьбе № 2 расчищены нижние части, по крайней мере, двух, прямоугольных в плане, обжигательных горнов, топочная камера которых была облицована поставленными на ребро квадратными сырцовыми кирпичами. Надо полагать, конструкция этих горнов была близка или просто идентична конструкции двухъярусных прямоугольных горнов на городище Бабиш-Мулла 1 [Курманкулов, Утубаев, 2013, с. 114-115; рис. на с. 137].

На поселении Бабиш-Мулла 7, как уже отмечалось выше, раскопано семь обжигательных керамических горнов. По конструктивным признакам выделяются два типа специальных обжиговых устройств.

Тип 1 - прямоугольные в плане двухъярусные обжигательные горны с прямым вертикальным ходом горячих газов. Площадь и размеры ТК почти равны площади и размерам ОК. Большая часть продухов устроена в плоском перекрытии топочной камеры. К этому типу относится горн № 1, два горна в мастерской № 1 (горны № 2 и 3), а также горн № 5 в мастерской № 2 . От горна № 6 в этой же мастерской сохранилась только нижняя часть ТК, по этой причине о его конструкции нельзя сказать что-либо определенное.

Один из горнов этого типа (горн № 1) раскопан полностью. На основании полученных данных нам удалось в деталях выявить характерные конструктивные особенности, присущие этому типу обжиговых устройств. Вход в топку, ориентированную по линии ССВ-ЮЮЗ, был с юга. Это овальная в плане яма $(1 \times 0,64$ м), устроенная в пахсовом массиве, которая почти вертикально опущена немного ниже уровня ТК, дно которой зафиксировано на отметках -132 -127 от реперной точки. ТК была почти овальная в плане, при этом часть, обращенная к входу, была несколько уже, чем ССВ часть сооружения. Длина топочной камеры - 3,5 м, ширина в южной части - 0,9 м, в северной части - 1,2 м. В ходе раскопок удалось достоверно установить, что крайние РT, расположенные по периметру топочной камеры, выходили из топки под углом по отношению к ее вертикальной оси. Таким образом, увеличивалась площадь ОК. Размеры ее определяются лишь приблизительно по крайним продухам. Площадь была, как можно предполагать, немногим менее 10 кв. м - 3,6×2,7 м. Под обжигательной камеры, верхний уровень которого зафиксирован на отметках $-5--12$ от реперной точки ${ }^{3}$, представляет собой плотную сильно прокаленную поверхность желто-краснооранжевого цвета. На поверхности 
пода четко прослеживаются округлые в плане продухи, которыми заканчиваются РТ, устроенные в перекрытии топочной камеры. Диаметр продухов в верхней части, на выходе в обжигательную камеру, - 8-12 см. Как можно предполагать, они располагались в площади обжигательной камеры в четыре ряда. На уровне пода расчищено 16 продухов, но так как часть перекрытия топочной камеры обвалилось, можно предполагать, что их было больше, не менее 20 (рис. 6; А, I).

Стены топочной камеры шириной $0,7-0,8$ м сложены из плотной пахсы. Нижняя часть топки была заглублена на 30-45 см от уровня древнего такыра, который в северозападной части раскопа зафиксирован на отметках $-100--107$ от реперной точки (рис. 6; А, III). Таким образом, топка горна № 1 возвышалась над древней дневной поверхностью, по крайней мере, на 1 м. Способ перекрытия ТК остается неясным. Можно с уверенностью говорить, что свода здесь не было; ни одного сырцового кирпича в процессе раскопок не обнаружено. Предполагаем, что оно было плоским на деревянном каркасе, который не сохранился: в пахсовых стенах с внешней стороны обнаружены округлые в поперечном сечении отверстия диаметром 7-8 см. Возможно, это следы от горизонтальных жердей. Отметим, что следы деревянных жердей (5-7 см в диаметре), надо полагать, уложенных горизонтально, отмечены и в стенах топочной камеры горна № 2 (Мастерская № 1). Если это действительно так, то перекрытие топочной камеры можно реконструировать следующим образом. На стены топки укладывались деревянные жерди каркаса, которые переплетались прутьями. Затем эта конструкция тщательно обмазывалась толстым слоем глины с обеих сторон. В процессе эксплуатации горна глина обжигалась до состояния обожженного кирпича, а прутья и жерди выгорали. Аналогичный прием, применявшийся при сооружении перекрытия топки, зафиксирован в одном из горнов конца V-IV вв. до н.э. на поселении Саратепа 2, в окрестностях Самарканда, где в плоском перекрытии выявлены следы деревянной арматуры [Иваницкий, 1992, с 23].

Тип 2. К этому типу относятся два горна - № 7 (мастерская № 3) (рис. 5) и отдельно расположенный горн № 4 (рис. 7). Оба двухъярусных обжигательных горна с прямым вертикальным ходом горячих газов раскопаны полностью. Основным отличием этих обжиговых устройств от горнов 1-го типа является форма ОК. В обоих случаях она круглая диаметром от 4,4 м (горн № 4) до 5,2 м (горн № 7). Можно осторожно предполагать, что стены ОК камеры горна № 4 были сложены из сырцового кирпича. Во всяком случае, в северной части, на месте предполагаемого входа в ОК, расчищено несколько кирпичей размерами $-50 \times 28 \times$ ? см; $50 \times 30 \times$ ? см. Стены ТК построены на уровне материка из блоков пахсы высотой 45-55 см. Ширина стен - 0,6-0,8 м. Стены ОК горна № 7 толщиной - 1,2-1,4 м сохранились несколько лучше. Они, также как и стены ТК, были построены из плотной пахсы серо-коричневого цвета. Массив пахсовой кладки был армирован деревянными жердями, которые разделяли пахсовые блоки. При зачистке горизонтальной поверхности сохранившейся части стен горна четко прослеживается два ряда пахсовых блоков, уложенных по периметру обжигательной камеры и разделенных деревянными жердями. Жерди диаметром или шириной 5-10 см четко прослеживаются по древесному 

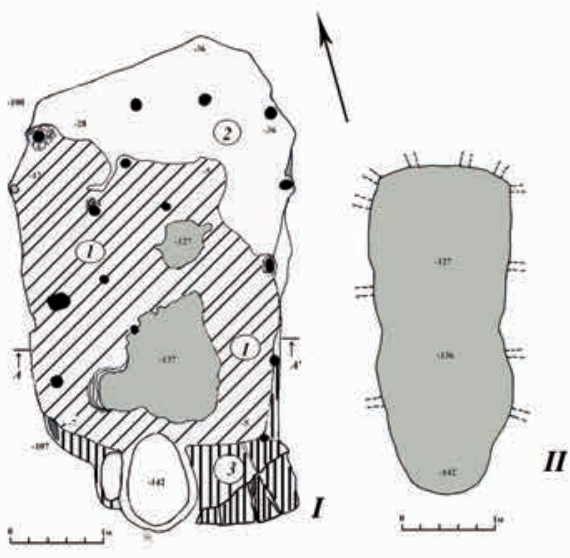

Усаювиме обозиачепия.

I.1 - прокаленная до красно-оранжевого цвета плотная поверхность пода обжигательной камеры.

1.2 - обожженная до красного чвета ганна. I.3 - naxca

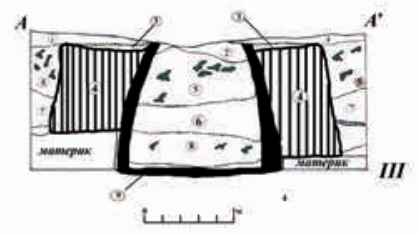

Условные обозначения.

III.I - рыхлая пылевиная супесь серого швета (слой надувного лесса)

III.2 - слой плотной супеси серого швета.

III.3 - прокаленные до красиа глиняные обмазки. III.4- пахсовыс стены

III.5 - рыхлый комковатый сугаинок с

большим кол-вом кусков керамического

швака.

III. 6- глинисто-супесчаные иатеки

III. 7 - плотная супесь серо-коричневого пвета

III.8 - плопыый комковатый суганнок

III.9 - слой золы и пепла с большим кол-вом древесных угольков.

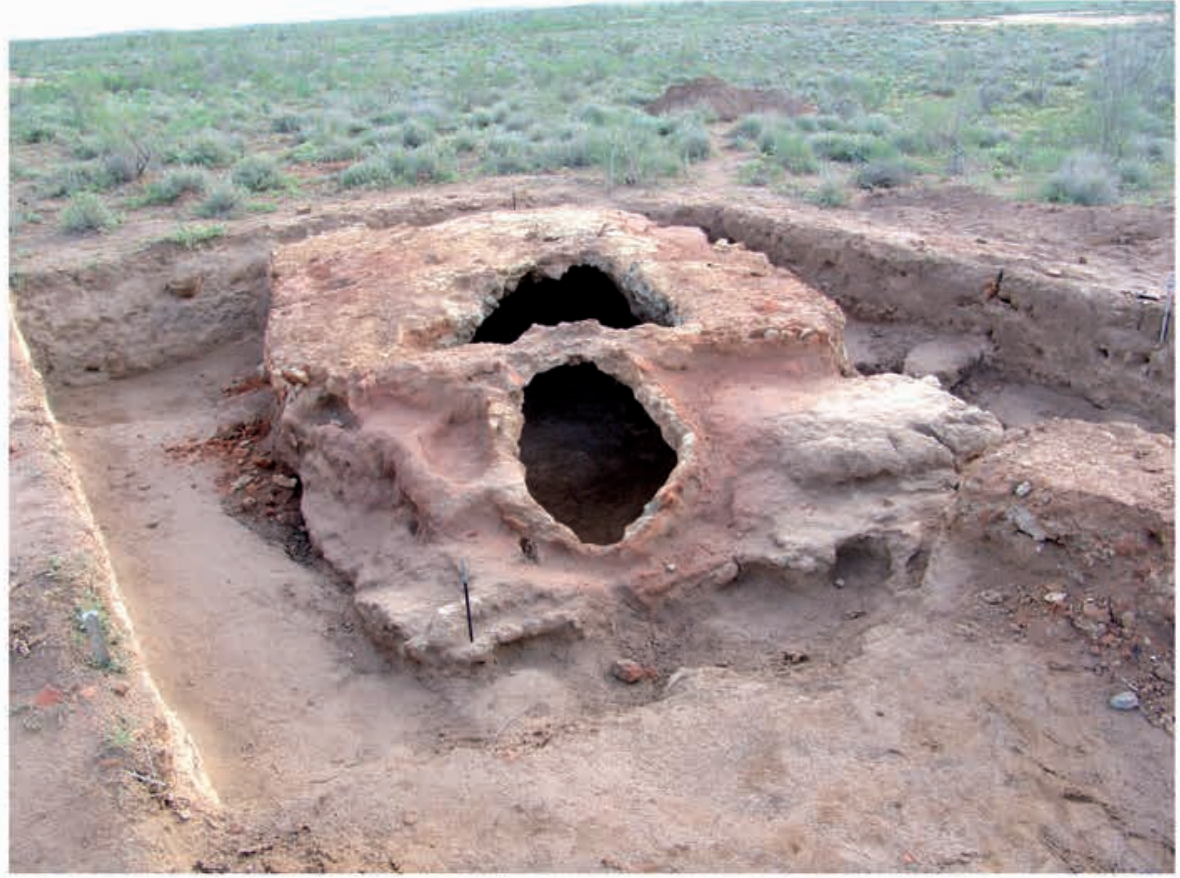

А- горн №1. План и разрез топочной камеры.

Б- горн №1. Фото, вид с юга.

Рис. 6. Бабиш-Мулла 7. Горн № 1

Fig. 6. Babish-Mulla 7. Horn No. 1 
тлену. Ширина пахсовых блоков 4070 см. Кроме того, деревянные жерди укладывались и радиально (рис. 5).

ТК в горнах 2-го типа, которые частично вырублены в материковом грунте, были овальными в плане. Следует заметить, что длина топки горна № 4 почти в два раза превышают длину ТК горна № 7. Высота топочной камеры, ширина которой у обоих горнов не превышала 0,8 м, от уровня пола до перекрытия - 1,3-1,5 м. Есть основание полагать, что топка у горнов этого типа была перекрыта поставленными под углом на ребро прямоугольными сырцовыми кирпичами - «стреловидный свод». Во всяком случае, фрагменты оплавленных и обожженных сырцовых кирпичей отмечены на стенках и в заполнении ТК горна № 4. Кроме того, поставленными на ребро сырцовыми кирпичами были облицованы стенки входа в топку горна № 4 (рис. 7: А).

Подача горячих газов из топки в ОК осуществлялась через РТ, которые расположены параллельно или почти параллельно друг другу, но под прямым углом к центральной оси ТК (рис. 7). РТ начинались на высоте 7080 см от пола ТК и под углом отходили вверх, где открывались продухами на уровне пода ОК. В сохранившейся части пода ОК горна № 4 расчищено пять округлых в плане продухов диаметром 10-12 см (рис. 5), но их, несомненно, было больше. По всей видимости, один ряд продухов располагался по периметру вплотную к стене ОК. Можно предполагать, что в центре ОК было еще несколько продухов, которыми заканчивались вертикальные РТ, устроенные непосредственно в центральной части перекрытия топки.

Перед входом в топочную камеру горна № 4 обнаружены следы, надо полагать, ветрозащитного устройства. В небольшом приямке шириной 1 м и глубиной 35-40 см обнаружены две столбовые ямки диаметром 10-12 см (рис. 5, А). По всей видимости, это следы вертикальных стоек, на которые мог опираться щит, закрывавший устье топочной камеры, который, возможно, еще и прикрывал вход от ветра.

На основании данных, полученных в последние годы, в результате раскопок поселения гончаров БабишМулла 7 уверенно можно говорить о двух типах обжигательных горнов, открытых на памятнике. Они различаются, прежде всего, по конструктивным признакам: форма ОК и способ перекрытия ТК. Возможно, как отдельный тип можно рассматривать остатки горнов, открытых на городище Бабиш-Мулла 1. Так как от них сохранилась только топочная камера, форма ОК нам неизвестна. Можно только предполагать, что она была прямоугольной. Также о характере перекрытия ТК мы можем только догадываться. Есть основание предполагать, что топка, ширина которой менее 1 м, была перекрыта поставленными наклонно сырцовыми кирпичами [Воробьева, 1961, с. 171; Вайнберг, Левина, 1993, с. 24]. Если это действительно так, то горны на Бабиш-Мулле 1 и, возможно, на поселении Баланды можно рассматривать как промежуточный тип обжиговых устройств.

Исследования поселения Бабиш-Мулла 7 однозначно дают все основания полагать, что на территории Нижней Сырдарьи в эпоху античности - III-II вв. до н.э. успешно функционировало крупное специализированное гончарное производство, расположенное в ближайшей округе столичного центра - городища Бабиш-Мулла. Памятник можно ква- 


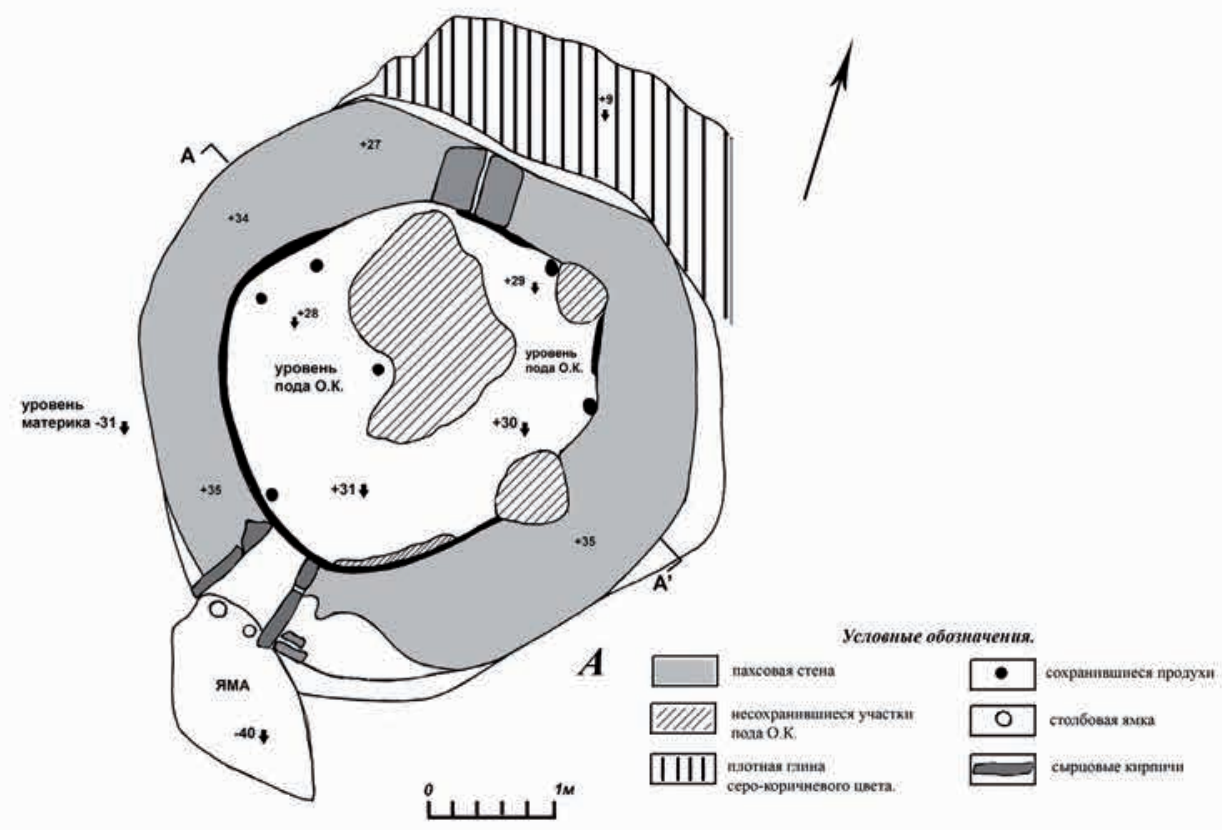

$$
\text { Gabom-Myasan } 72016
$$
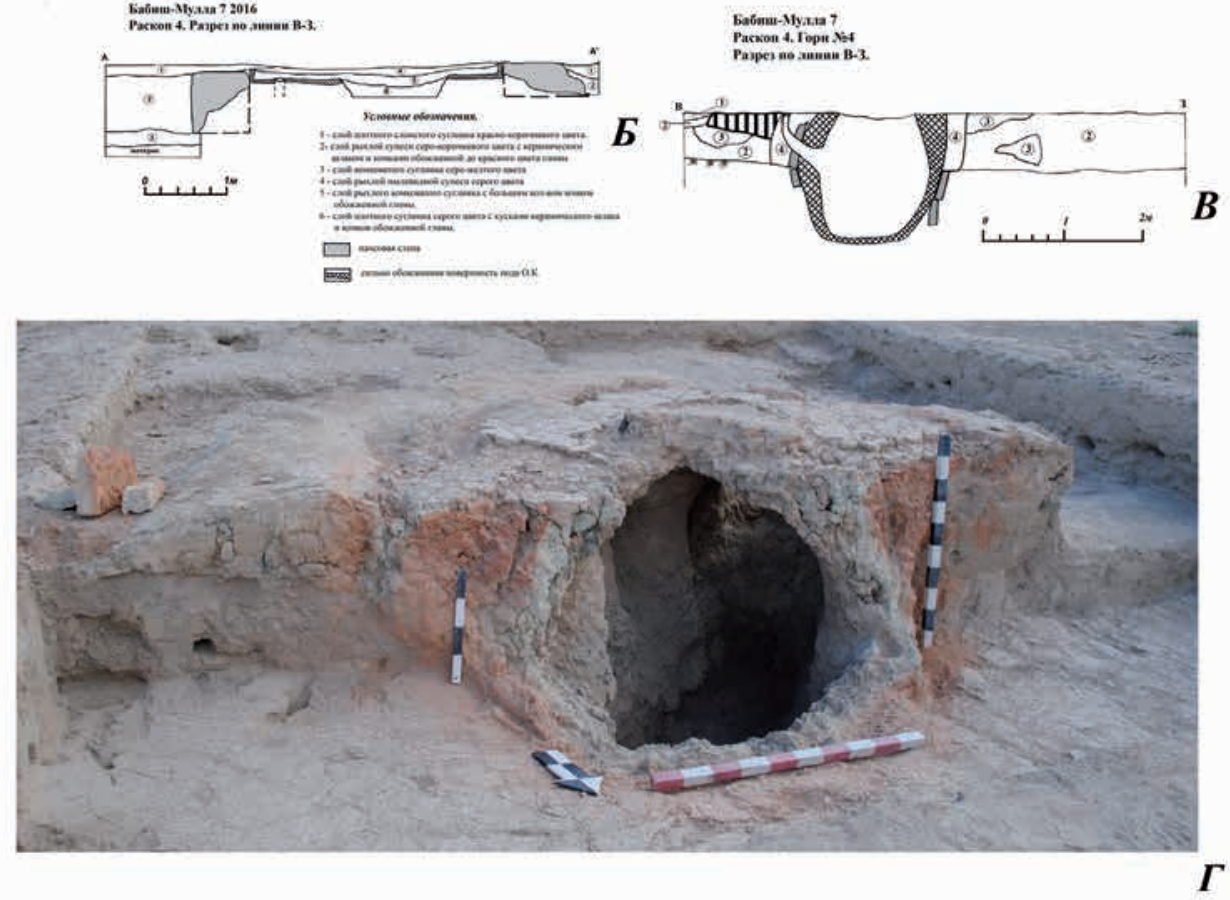

Рис. 7. Бабиш-Мулла 7. Горн № 4

Fig. 7. Babish-Mulla 7. Horn No. 4 
Болелов С.Б., Утубаев Ж.P. Гончарное производство на территории древней дельты Сырдарьи в эпоху античности: новые данные

лифицировать как специализированное ремесленное поселение.

В южном Приаралье, прежде всего в Хорезме, известно некоторое количество производственных гончарных центров. По объему производства они вполне сопоставимы с поселением Бабиш-Мулла 7. Однако в Хорезме это были сезонные производства [Болелов, 2013a, с. 35-37], тогда как Бабиш-Мулла 7 было постоянным поселением, работавшим круглый год. Об этом красноречиво свидетельствуют остатки жилых построек и довольно крупная усадьба в северной его части. Кроме того, необходимо отметить мастерскую, расположенную рядом с горнами № 2, 3, в которой можно было работать круглый год. На территории Южного Приаралья это второй случай, когда здание мастерской располагалось в непосредственной близости от обжигательного горна. На поселении Хумбузтепа в южном Хорезме, которое также являлось крупным производственным центром, открыт обжигательный горн и часть мастерской рядом с ним, которые датируются не позднее конца VI в. до н.э. Также как и в мастерской на Бабиш-Мулле 7, на Хумбузтепа найдены хумы с кусками пластичной производственной глины и фрагментами сформованных, но необожженных сосудов [Болелов, 2013б, c. 81].

На территории Хорезма в античный период по археологическим данным фиксируются три организационные формы ремесленного производства, представленные несколькими типами памятников:

- общинное ремесло - одиночные горны на территории поселений;

- ремесленное сезонное производство - небольшие гончарные центры на берегах каналов на территории земледельческих оазисов;
- крупное специализированное ремесленное производство - крупные гончарные центры и специализированные или многофункциональные ремесленные поселения на окраинах оазиса [Болелов, 2002, с. 11-13;2013в, c. 15-16].

На территории Нижней Сырдарьи по археологическим данным зафиксированы пока только две организационные формы гончарного производства: общинное ремесло - обжигательные горны на поселении Баланды и крупное специализированное постоянное гончарное производство - Бабиш-Мулла 7. Обращает на себя внимание одно, на наш взгляд, немаловажное обстоятельство. Поселение Бабиш-Мулла 7 находится практически в центре земледельческого оазиса, ремесленные поселения и крупные производственные центры Хорезма располагались на северо-западной границе области в зоне контактов со скотоводами-кочевниками, оставившими многочисленные курганные могильники в Присаракамышье, возможно в районе постоянных зимовок. Именно на эти группы кочевников и было ориентировано товарное производство ремесленных поселений [Вайнберг, 1981, с. 125; 1999, с. 108 109]. Курганных могильников IVII вв. до н.э., которых определенно можно было бы связать с кочевниками в области среднего течения Жанадарьи, пока не обнаружено. Таким образом, нет никаких оснований считать, что гончарное производство в окрестностях Бабиш-Муллы было ориентировано на кочевников или группы скотоводов, проживавших в пределах земледельческого оазиса. С уверенностью можно говорить, что основными потребителями продукции производственного керамического центра были жители ирригационного района. 
В связи с этим обращает на себя внимание крупная усадьба в северной части поселения. Надо полагать, по размерам и планировке она отличалась от остальных построек на поселении. Кроме того, в непосредственной близости от усадьбы нет следов производства. Учитывая все это, весьма заманчиво квалифицировать это здание как усадьбу управляющего или главы поселения, контролировавшего процесс производства. Кроме того, следует отметить, что производственный центр расположен в непосредственной близости от центра оазиса - городища Бабиш-Мулла и следов других гончарных производств на территории оазиса до сих пор не зафиксировано. На раннем этапе функционирования поселения к нему был подведен канал, что само по себе сопряжено с использованием значительных трудовых ресурсов. Все эти факты дают некоторые основания предположить, что производственный центр мог работать под контролем центральной власти, который осуществлялся управляющим и возник, может быть, не без ее участия.

Несколько подробней следует остановиться на конструкции обжигательных горнов 1-го типа, открытых на поселении. Прямоугольные в плане горны, которые датируются последней третью I тыс. до н.э., не известны не только на территории Южного Приаралья, но и всей Средней Азии. Единственная историкокультурная область на Среднем Востоке, где в эпоху античности использовалась прямоугольная двухъярусная конструкция - это Бактрия. Здесь прямоугольные обжигательные горны со сводчатым перекрытием топочной камеры появляются не ранее рубежа н.э., а до этого времени на территории области, также как и во всей
Средней Азии, были только округлые двухъярусные обжигательные горны [Болелов, 2001, с. 21-22; 2010, с. 27]. При этом следует заметить, что и у прямоугольных, и у округлых в плане горнов камера была полностью заглублена ниже уровня древней поверхности. Горны, раскопанные на БабишМулла 7, являются уникальными по двум причинам. Во-первых, они, также как и на городище Бабиш-Мулла, были прямоугольными или близкими к прямоугольным в плане. Во-вторых, топочная камера, в отличие от всех остальных среднеазиатских горнов III-II вв. до н.э., построена из пахсы практически на уровне древней дневной поверхности. Не вызывает сомнения тот факт, что прямоугольные двухъярусные обжигательные горны появляются в низовьях Сырдарьи уже как готовая, полностью сформировавшаяся конструкция, причем привнесенная извне. Во всяком случае, специальных устройств для высокотемпературного обжига керамики, которые можно было бы датировать до III в. до н.э., в низовьях Сырдарьи пока не обнаружено. Вся местная керамика сакского периода лепная и была обожжена в костре

Единственной, но отнюдь не прямой и весьма отдаленной территориально аналогией горнам БабишМулла 7 являются специальные обжиговые устройства, раскопанные в Западном Прикаспии, на территории Кавказской Албании. Они представляли собой двухъярусное прямоугольное в плане сооружение из сырцовых кирпичей. Топочная камера перекрывалась сводом, опиравшимся на прямоугольные выступы на стенках топки. Здесь следует заметить, что стены топочной камеры, независимо от того, сооружалась ли она в специально вырытом котловане или была немного 
Болелов С.Б., Утубаев Ж.Р. Гончарное производство на территории древней дельты Сырдарьи в эпоху античности: новые данные

заглублена в грунт, всегда строились из сырцовых кирпичей или пахсы. Самые ранние из этих горнов (Мингечаур) датируются III-ІІ вв. до н.э. [Ионе, 1949 , с. 42-52]. Такая конструкция обжигательных горнов практически без изменений существовала и в более позднее время [Халилов, 1965, c. 157-159].

Горны 2-го типа поселения Бабиш-Мулла 7 по конструктивным признакам очень близки горнам, раскопанным на городище Калалы-гыр 1 в Левобережном Хорезме, устроенным в цоколе крепостной башни уже давно запустевшего (или недостроенного) городища. Топочная камера была перекрыта стрельчатым сводом в виде двух наклонно поставленных и опирающихся друг на друга сырцовых кирпичей. Следует заметить, что такой же тип перекрытия прослеживается и у горна, открытого на Бабиш-Мулле 7 и, возможно, на городище Бабиш-Мулла 1. Расположение РТ у горна № 4 полностью соответствует конструкции тепловодноразделительного блока (ТРБ - по А. А. Бобринскому) у горнов на городище Калалы-гыр 1 [Воробьева, 1959, с. 210]. Таким образом, горны на Калалы-гыр 1 являются практически полной аналогией горну № 4 на поселении Бабиш-Мулла 7. Разница состоит лишь в том, что топка горнов на Калалы-гыр 1 вырублена в строительной конструкции (цоколь башни), а ТК горна на Бабиш-Мулле 7 лишь на треть заглублена в материковый грунт и стены ее целиком сложены из пахсы. Значительный хронологический разрыв между этими двумя объектами, который составляет минимум 400 лет (горны Калалы-гыр 1 по сопутствующему материалу датируются II-III вв. н.э.), не дает основание связывать их напрямую.

\section{Заключение}

Начальный этап становления ремесленного гончарного производства в низовьях Сырдарьи по своему содержанию весьма схож с таким же процессом в низовьях Амударьи. И в том, и в другом случае это результат привнесенных на эти территории новых прогрессивных технологий. На территории Хорезма они появляются не позднее конца VII в. до н.э., видимо, в результате инфильтрации какихто групп населения и ремесленников из южных областей Средней Азии, в первую очередь, из районов дельты Мургаба, уже недостаточно обводненной в это время. Об этом достаточно красноречиво свидетельствует конструкция ранних хорезмийских горнов и комплекс керамики типа Яз II-III [Болелов, 2004; 2017]. На территории древней дельты Сырдарьи процесс становления гончарного производства, во всяком случае, учитывая имеющиеся в настоящее время археологические данные, во многом остается еще неясным. На основании анализа раннего керамического комплекса (нижние слои Чирик-Рабата, нижние слои Баланды 1) можно говорить о влиянии на гончарное производство чирикрабатской культуры керамической традиции Хорезма. Но это касается, прежде всего, форм и типов сосудов. Не исключено, что и гончарный круг мог попасть в низовья Сырдарьи из Хорезма, хотя это и не обязательно. Намного сложнее вопрос о появлении на берегах Жанадарьи двухъярусного обжигательного керамического горна. Как уже отмечалось выше, на территории античной Средней Азии неизвестно даже отдаленных параллелей чирикрабатским горнам 1-го типа. Мы можем высказать по этому поводу лишь некоторые соображения. 
В последней трети I тыс. до н.э. функционировал водный путь по Узбою, который через Каспий связывал Хорезм и области Западного и Юго-Западного Прикаспия [Болелов, 2005, с. 229-232]. В это же время функционировал торговый сухопутный путь из Хорезма в область древней дельты Сырдарьи. Об этом свидетельствуют находки импортных, не только хорезмийских вещей, но и предметов из Северного Причерноморья и Закавказья на памятниках чирикрабатской культуры [Болелов, 2015 , с. 24-25]. Учитывая это обстоятельство, в качестве предварительной рабочей гипотезы можно предположить, что по этим торговым путям импортировались не только предметы роскоши, но и новые прогрессивные технологии и идеи. Возможно, именно с этим связано появление не позднее начала III в. до н.э. далеко на Востоке, в низовьях Сырдарьи, совершенно новой производственной конструкции - двухъярусного прямоугольного обжигательного горна с прямым вертикальным движением горячих газов, не известного ранее не только в Приаралье, но и на всей территории Центральной Азии.

\section{Примечания}

1 - На территории Средней Азии наиболее полно изучено сельское жилище Хорезма [Неразик, 1976], по этой причине сравнивать приходится жилищем этой области, наиболее территориально близкой низовьям Сырдарьи. Кроме, того нельзя не учитывать и культурной близости двух этих областей, во всяком случае на раннем этапе формирования чирикрабатской культуры.

2 - Здесь и далее используются термины и названия, предложенные А.А. Бобринским (см.: [Бобринский, 1991]).

3 - За реперную точку принята поверхность такыра к западу от раскопа.

\section{ЛИТЕРАТУРА}

1. Бобринский А.А. Гончарные мастерские и горны Восточной Европы. М.: Наука, 1991. $213 \mathrm{c.}$

2. Болелов С.Б. Гончарная мастерская III-II вв. до н.э. на Кампыртепа (К вопросу о керамическом производстве и организации ремесла Северной Бактрии эпохи эллинизма). // Археологические исследования Кампыртепа. Материалы ТЭ, вып. 2. Ташкент: SAN'AT, 2001. C. 15-30.

3. Болелов С.Б. К вопросу о формах ремесленного керамического производства на территории Средней Азии в древности (конец I тыс. до н.э. - начало I тыс. н.э.). // Материальная культура Востока. М., 2002. Вып. 3. С. 3-23.

4. Болелов С.Б. К вопросу о периодизации раннего этапа истории Древнего Хорезма. // TRANSOXIANA. История и культура. Ташкент; М.: изд-во Р. Элинина, 2004. C. $48-54$.

5. Болелов С.Б. К вопросу о южных и юго-западных связях Хорезма во второй половине I тыс. до н.э. по археологическим данным (древнехорезмийский археологический комплекс) // Центральная Азия. Источники, история, культура. М.: Восточная литература, 2005. С. 215-234.

6. Болелов С.Б. Гончарные производства Бактрии античного периода // Древние цивилизации на древнем Востоке. М.: ГМВ, 2010. С. 26-28. 
Болелов С.Б., Утубаев Ж.Р. Гончарное производство на территории древней дельты Сырдарьи в эпоху античности: новые данные

7. Болелов С.Б. Ремесло Древнего Хорезма на ранних этапах развития государственности // Согдийцы, их предшественники, современники и наследники. Труды ГЭ, LXII. СПб.: изд-во ГЭ, 2013а. C. 29-44.

8. Болелов С.Б. Ремесло древнего Хорезма по археологическим данным. Этапы становления // РА. 2013б. № 2. С. 77-86.

9. Болелов С.Б. Ранний этап становления ремесленного производства на территории Хорезма (вторая половина I тыс. до н.э.) // Приаралье на перекрестке культур. Самарканд: МИЦАИ, 2013в. С. 5-19.

10. Болелов С.Б. Древний Хорезм на перекрестке торговых путей во второй половине I тыс. до н.э. // Вестник истории литературы и искусства ОИФН РАН. Т. Х. М.: Собрание, 2015. С. 7-33.

11. Болелов С.Б. Оазис среди песков (Древний Хорезм в системе трансконтинентальных и торговых связей во второй половине I тыс. до н.э.) // Цивилизации Великого Шелкового пути из прошлого в будущее: перспективы естественных, общественных, гуманитарных наук: матер. междунар. науч. конф. (г. Самарканд, 28-29 сентября 2017 г.). Самарканд: МИЦАИ, 2017. С. 77-94.

12. Вайнберг Б.И. Скотоводческие племена в Древнем Хорезме // Культура и искусство Древнего Хорезма. М.: Наука, 1981. С. 121-130.

13. Вайнберг Б.И. Этногеография Турана в древности VII в. до н.э. - VIII в. н. э.. М.: Идрик, 1999. 359 с.

14. Вайнберг Б.И., Левина Л.М. Чирикрабатская культура. Низовья Сырдарьи в древности. Вып. 1. М.: ИЭА РАН, 1993. 130 с.: ил.

15. Воробьева М.Г. Опыт картографирования гончарных печей для историкоэтнографического атласа Средней Азии и Казахстана. // Материалы к историкоэтнографическому Атласу Средней Азии и Казахстана. Труды ИЭ АН СССР, новая серия, т. XLVIII. М.; Л.: Издательство АН СCCP, 1961. С. 147-179.

16. Иваницкий И.Д. Саратепе 2 - поселение керамистов середины I тыс. до н.э. под Самаркандом // ИМКУ. 1992. Вып. 26. С. 22-40.

17. Ионе Г.И. Гончарные печи древнего Мингечаура // КСИИМК. 1949. Вып. XXIV. C. 42-54.

18. Курманкулов Ж.К., Утубаев Ж.Р. Баланды (Буланды) памятник античности. Книга-альбом. Алматы: Институт археологии им. А.Х. Маргулана, 2013. 148 с.

19. Неразик E.E. Сельское жилище в Хорезме (I-XIV вв.). Труды ХАЭЭ, т. IX. М.: Наука, 1976. 256 с.

20. Толстов С.П., Жданко Т.А., Итина М.А. Работы Хорезмской археологоэтнографической экспедиции АН СССР в 1958-1961 гг. // Полевые исследования Хорезмской экспедиции в 1958-1961 гг. Памятники первобытного и античного времени. Материалы ХАЭ. Вып. 6. І. М.: Наука, 1963. С. 3-91.

21. Утубаев Ж.Р., Болелов С.Б. Новые археологические открытия в низовьях Сырдарьи // Вестник КемГУ. 2016. Вып. 1 (65). Т. 4. С. 56-63.

22. Халилов Дж.А. Археологически памятники I тыс. у села Худжбала в Азербайджанской ССР // СА. 1965. № 3. С. 154-162.

\section{Сведения об авторах:}

Болелов Сергей Борисович - кандидат исторических наук, Государственный музей искусства народов Востока (г. Москва, Росиия); bsb1958@yandex.ru

Утубаев Жанболат Раймкулович - кандидат исторических наук, Институт археологии им. А.Х. Маргулана (г. Алматы, Казахстан); utubaev_z@mail.ru 


\title{
СЫРДАРИЯНЫҢ ЕЖЕЛГІ АРНАСЫНДАҒЫ АНТИКАЛЫҚ ҚЫШ ӨНДІРІСІ: ЖАНА МӘЛІМЕТТЕР БОЙЫНША
}

\author{
С. Б. Болелов, Ж. Р. Утубаев
}

Мақалада Сырдарияның ежелгі арнасында б.д.д. I мыңжылдықтың екінші жартысында Шірікрабат археологиялық егіншілік мәдениеті таралған, БәбішМола 7 елді-мекенінде бірнеше жыл жүргізілген қазба жұмыстарының нәтижелері жарияланады. Бәбіш-Мола 7 б.д.д. III-II ғғ. егіншілік оазис тұрғындарын қыш ыдыстармен қамтамассыз еткен ірі қыш өндіріс орталығы. Елді-мекенде екі қабатты қыш күйдіруге арналған пештер ашылды. Бірінші типтегі тікбұрыш пішінді пештер құрылымдық белгілері бойынша Орта Азия аумағында кездесетін пештерге ұқсастығы жоқ. Пештер жанынан ыдыстар дайындауға арналған өндірістік бөлмелердің орны қазылды.

Түйін сөздер: археология, ежелгі егіншілік мәдениеті, елді-мекен, өндірістік орталық, екі қабатты қыш күйдіретін пеш, керамика, қыш шеберханасы

\section{POTTERY PRODUCTION ON THE TERRITORY OF THE ANCIENT SYRDARYA DELTA IN THE AGE OF ANTIQUITY: NEW DATA}

\section{S. B. Bolelov, Zh. R. Utubayev}

The article publishes the results of several years of excavation in the settlement of Babish-Mulla 7, in the ancient delta of the Syrdarya, where in the second half of the 1st millennium BC the agricultural Chirik-rabat archaeological culture was widespread. Babish-Mulla 7 is a large industrial pottery center of the III-II centuries BC, which supplied the population of a large agricultural oasis with ceramics. Two types of two-level ceramic kilns were opened in the settlement. Rectangular kilns of the first type have no analogies in Central Asia by their design features. Next to the kilns were excavated industrial premises, where dishes were made.

Keywords: archaeology, ancient agriculture, settlement, production center, two-level burning ceramic kiln, ceramics, pottery workshop

\section{REFERENCES}

1. Bobrinskiy, A. A. 1991. Goncharnye masterskie i gorny Vostochnoy Evropy (Pottery workshops and horns of Eastern Europe). Moscow: "Nauka" Publ. (in Russian).

2. Bolelov, S. B. 2001. In Arheologicheskie issledovaniya Kampyrtepa (Archaeological research of Kampyrtepa), 2. Tashkent: “SAN'AT” Publ., 15-30 (in Russian).

3. Bolelov, S. B. 2002. Materialnaya kultura Vostoka (Material culture of the East), 3. Moscow, 3-23 (in Russian).

4. Bolelov, S. B. 2004. TRANSOXIANA. Istoriya i kultura (TRANSOXIANA. History and culture). Tashkent; Moscow: R. Elinina Publ., 48-54 (in Russian).

5. Bolelov, S. B. 2005. In Antonova, E. V., Mkrtychev, T. K. (eds.). Tsentralnaya Aziya. Istochniki, istoriya, kultura (Central Asia. Sources, history, culture). Moscow: "Vostochnaya literature" Publ., 215-234 (in Russian).

6. Bolelov, S. B. 2010. In Drevnie civilizacii na drevnem Vostoke (Ancient civilizations in the ancient East). Moscow: State Museum of the East Publ., 26-28 (in Russian).

7. Bolelov, S. B. 2013a. In Lurie, P. B., Torgoev, A. I. (eds.). Sogdiycy, ih predshestvenniki, sovremenniki i nasledniki (Sogdians, their predecessors, contemporaries and heirs). Saint Petersburg: State Hermitage Publ., 29-44 (in Russian).

8. Bolelov, S. B. 2013b. In Rossiyskaya arheologiya (Russian archeology), 2, 77-86 (in Russian). 
Болелов С.Б., Утубаев Ж.Р. Гончарное производство на территории древней дельты Сырдарьи в эпоху античности: новые данные

9. Bolelov, S. B. 2013c. In Priaralie na perekrestke kultur (Aral Sea region at the crossroads of cultures). Samarkand: International Institute for Central Asian Studies Publ, 5-19 (in Russian).

10. Bolelov, S. B. 2015. In Urilov, I. Kh. (ed.). Vestnik istorii literatury i iskusstva (Bulletin of the history of literature and art), 10. Moscow: "Sobranie" Publ., 7-33 (in Russian).

11. Bolelov, S. B. 2017. In Tsivilizatsii Velikogo Shelkovogo puti iz proshlogo v budushchee (Civilizations of the Great Silk Road from the past to the future). Samarkand: International Institute for Central Asian Studies Publ., 77-94 (in Russian).

12. Weinberg, B. I. 1981. In Kultura i iskusstvo Drevnego Khorezma (Culture and art of Ancient Khorezm). Moscow: "Nauka" Publ., 121-130 (in Russian).

13. Weinberg, B. I. 1999. Etnogeografiya Turana v drevnosti VII v. do n.e. - VIII v. n.e. (Ethnographic Geography of Turan in Antiquity of the $7^{\text {th }}$ Century $B C-8^{\text {th }}$ century $A D$ ). Moscow: "Idrik" Publ. (in Russian).

14. Weinberg, B. I., Levina, L. M. 1993. Chirikrabatskaya kultura. Nizoviya Syrdarii $v$ drevnosti (Chirikrabat culture. The lower reaches of the Syrdarya in antiquity). Moscow: Ethnology and Anthropology Institute RAS (in Russian).

15. Vorobyova, M. G. 1961. In Trudy IE AN SSSR (Proceedings of IE USSR Academy of Sciences), XLVIII, 147-179 (in Russian).

16. Ivanitsky, I. D. 1992. In Istoriya materialnoy kultury Uzbekistana (History of material culture of Uzbekistan), 26, 22-40 (in Russian).

17. Ione, G. I. 1949. In Kratkie soobshcheniya Instituta istorii materialnoy kultury (Brief Communications from the Institute of the History of Material Culture), XXIV, 42-54 (in Russian).

18. Kurmankulov, Zh. K., Utubayev, Zh. R. 2013. Balandy (Bulandy) pamyatnik antichnosti (Balandy (Bulandy) is a monument of antiquity). Almaty: A.Kh. Margulan Institute of Archeology Publ. (in Russian).

19. Nerazik, E. E. 1976. Selskoe zhilishche v Horezme (I-XIVvv.). (Rural dwelling in Khorezm (I-XIV centuries)). Moscow: "Nauka" Publ. (in Russian).

20. Tolstov, S. P., Zhdanko, T. A., Itina, M. A. 1963. In Polevye issledovaniya Horezmskoy ekspeditsii v 1958-1961 gg. (Field studies of the Khorezm expedition in 1958-1961). Moscow: "Nauka" Publ., 3-91 (in Russian).

21. Utubayev, Zh. R., Bolelov, S. B. 2016. In Bulletin of Kemerovo State University, 1 (65), 56-63 (in Russian).

22. Khalilov, J. A. 1965. In Soviet archeology, 3, 154-162 (in Russian).

\section{About the Authors:}

Bolelov Sergey B. Candidate of historical sciences, State Museum of Oriental Art, Moscow, Russia; bsb1958@yandex.ru

Utubayev Zhanbolat R. Candidate of historical sciences, A.Kh. Margulan IArcheology Institute, Almaty, Kazakhstan; utubaev_z@mail.ru

\footnotetext{
Мүдделер қақтығысы туралы ақпаратты ашу. Авторлар мүдделер қақтығысының жоқтығын мәлімдейді. / Раскрытие информации о конфликте интересов. Авторы заявляют об отсутствии конфликта интересов. / Disclosure of conflict of interest information. The authors claims no conflict of interest.

Мақала туралы ақпарат / Информация о статье / Information about the article. Редакцияға түсті / Поступила в редакцию / Entered the editorial office: 05.02.2020.

Рецензенттер мақұлдаған / Одобрено рецензентами / Approved by reviewers: 12.02.2020. Жариялауға қабылданды / Принята к публикации / Accepted for publication: 19.02.2020.
} 